The last Bulletin de la Société de Geographie (1 ${ }^{\text {er }}$ Trimestre, I885), contains a paper by M. de Mailly-Chalon on a journey in Manchuria. With two countrymen he left Peking for Newchwang, and thence passing to the east of Moukden, through Kirin to Ninguta, where the party turned to the south-east along the Tiumen, towards the ocean, and reached Vladivostock. The journey the whole way was along the Corean frontier. Leaving Vladivostock the travellers crossed Siberia to Tomsk, from which they went to Samarkand. From this point the story of the journey is taken up by another member of the party, Baron Benoist-Méchin, whose paper on the journey across Turkestan succeeds M. Mailly-Chalon's. This journey led them from Samarkand through Karshi, to Bokhara, thence to the Amou-Darya at Charjui. They followed the river then down to Petro-Alexandrovsk, whence they deviated to Khiva. From the latter town they retraced their steps up the river, and from Kurgan-Chin started across the Kara-Kum to Merv, and so to Sarakhs and Persian territory at Meshed. The journey, here barely indicated, lasted two years, i.e. from the departure from Japan for Peking to the arrival in Teheran. M. Rabot writes on Nordenskjöld's expedition to Greenland, the paper being compiled from the Professor's reports to Mr. Oscar Dickson, published in the Fournal of the Swedish Society of Anthropology and Geography. M. Charles Huber brings to an end his long journeys in Central Arabia, between I878 and 1882, to which we have adverted in noticing previous numbers of the Bulletin.

AT the meeting of the Paris Geographical Society on the 7 th inst., M. Giraud was received with great distinction, and detailed his recent travels in Africa. The explorer has received the gold medal of the Society and the Cross of the Legion of Honour.

\section{ASTRONOMICAL PHENOMENA FOR THE WEEK, 1885, APRIL 19-25}

(FOR the reckoning of time the civil day, commencing at Greenwich mean midnight, counting the hours on to 24 , is here employed.)

\section{At Greenwich on April 19}

Sun rises, 4 h. $57 \mathrm{~m}$. ; souths, IIh. $59 \mathrm{~m} .0^{\circ} 7 \mathrm{~s}$.; sets, I9h. Im. ; decl. on meridian, $\mathrm{II}^{\circ} 2 \mathrm{O}^{\prime} \mathrm{N}$. : Sidereal Time at Sunset, 8h. $53 \mathrm{~m}$.

Moon (at First Quarter on April 2I) rises, 8h. Iom. ; souths, I6h. $4 \mathrm{~m}$.; sets, $23 \mathrm{~h} .58 \mathrm{~m}$. ; decl. on meridian, $18^{\circ} 14^{\prime} \mathrm{N}$. Planet Rises Souths Sets Decl. on meridian

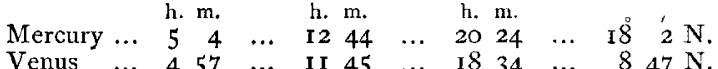
$\begin{array}{lllllllllllllll}\text { Venus } & \ldots & 4 & 57 & \ldots & \text { I I } & 45 & \ldots & \text { I8 } & 34 & \ldots & 8 & 47 & \mathrm{~N} .\end{array}$ $\begin{array}{lllllllllllllll}\text { Mars } & \ldots & 4 & 36 & \ldots & \text { I I } & 7 & \ldots & \text { I7 } & 38 & \ldots & 5 & 21 & \text { N. }\end{array}$ $\begin{array}{lllllllllllllllll}\text { Jupiter } & \ldots & 12 & 45 & \ldots & 20 & 2 & \ldots & 3 & 19 * & \ldots & \text { I4 } & 3 & \mathrm{~N} & \end{array}$ $\begin{array}{lllllllllllllll}\text { Saturn } & \ldots & 7 & \mathbf{2 2} & \ldots & \mathbf{1} 5 & 28 & \ldots & 23 & 34 & \ldots & \mathbf{2 2} & 3 & \mathrm{~N}\end{array}$ * Indicates that the setting is that of the following day. Occultations of Stars by the Moon

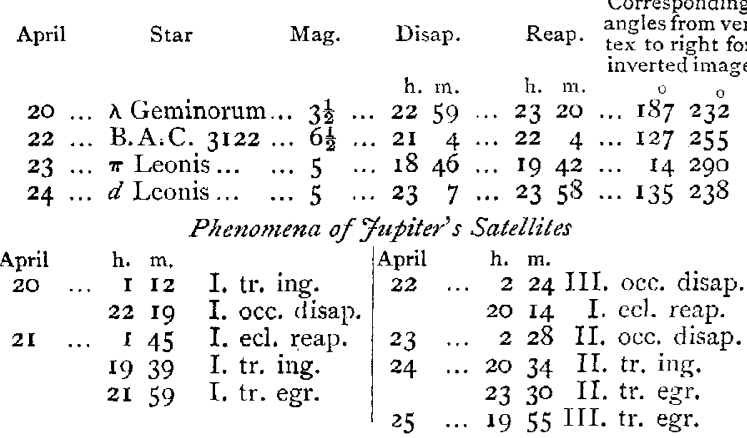

The Occultations of Stars and Phenomena of Jupiter's Satellites are such $s$ are visible at Greenwich.

\begin{tabular}{|c|c|c|c|c|}
\hline Apri & & h. & & \\
\hline I9 & $\ldots$ & I & $\ldots$ & $\begin{array}{l}\text { Saturn in conjunction with and } 4^{\circ} I^{\prime} \text { north } \\
\text { of the Moon. }\end{array}$ \\
\hline 22 & $\ldots$ & 3 & $\cdots$ & Jupiter stationary. \\
\hline 23 & $\ldots$ & 19 & $\cdots$ & $\begin{array}{l}\text { Jupiter in conjunction with and } 4^{\circ} 37^{\prime} \\
\text { north of the Moon. }\end{array}$ \\
\hline
\end{tabular}

\section{ON A REMARKABLE PHENOMENON OF CRYSTALLINE REFLECTION ${ }^{1}$ \\ Introduction.}

I N a letter to me, dated March 29, 1854 , the late Dr. W. Bird Herepath enclosed for me some iridescent crystals of chlorate of potash, which he thought were worth my examination. He noticed the intense brilliancy of the colour of the reflected light, the change of tint with the angle of incidence, and the apparent absence of polarisation in the colour seen by reflection.

The crystals were thin and fragile, and rather small. I did not see how the colour was produced, but I took for granted that it must be by some internal reflection, or possibly oblique refraction, at the surfaces of the crystalline plates that the light was polarised and analysed, being modified between polarisation and analysation by passage across the crystalline plate, the normal to which I supposed must be sufficiently near to one of the optic axes to allow colours to be shown, which would require no great proximity, as the plates were very thin. To make out precisely how the colours were produced seemed to promise a very troublesome investigation on account of the thinness and smallness of the crystals : and, supposing that the issue of the investigation would be merely to show in what precise way the phenomenon was brought about by the operation of well-known causes, I did not feel disposed to engage in it, and so the matter dropped.

But more than a year ago Prof. E. J. Mills, F.R.S., was so good as to send me a fine collection of splendidly coloured crystals of the salt of considerable size, several of the plates having an area of a square inch or more, and all of them being thick enough to handle without difficulty. In the course of his letter mentioning the despatch of the crystals, Prof. Mills writes: "They [the coloured crystals] are, I am told, very pure chemically, containing at most $\mathrm{O}^{\circ} \mathrm{I}$ per cent. foreign matter. They are rarely observed-one or two perhaps now and then in a large crystallisation ... I have several times noticed that small potassic chlorate crystals, when rapidly forming from a strong solution, show what I suppose to be interference colours ; but the fully formed crystals do not show them."

Some time later I was put into communication with $\mathrm{Mr}$. Stanford, of the North British Chemical Works, Glasgow, from which establishment the crystals sent me by Prof. Mills had come. Mr. Stanford obligingly sent me a further supply of these interesting crystals, and was so kind as to offer to try any experiment that I might suggest as to their formation.

On viewing through a direct-vision spectroscope the colours of the crystals which I had just received from Prof. Mills, the first glance at the spectrum showed me that there must be something very strange and unusual about the phenomenon, and determined me to endeavour to make out the cause of the production of these colours. The result of my examination is described in the present paper.

Section I.-Preliminary Physical Examination.-I. It will be necessary to premise that chlorate of potash belongs to the oblique system of crystallisation. The fundamental form may be taken as an oblique prism on a rhombic base, the plane bisecting the obtuse dihedral angle of the prism being the plane of symmetry. Rammelsberg denotes the sides of the prism by $\mathrm{P}$, and the base by $\mathrm{C}$, and gives for the inclinations of the faces $\mathrm{PP}=104^{\circ} 22^{\prime}$ and $\mathrm{CP}=105^{\circ} 35^{\prime}$. The face $\mathrm{C}$, which is perpendicular to the plane of symmetry, is so placed as to bring three obtuse plane angles together at two opposite corners of the parallelepiped. The salt usually forms flat, rhombic or hexagonal plates parallel to the $\mathrm{C}$ plane, the edges of the rhombus being parallel to the intersections of the $\mathrm{P}$ faces by the $\mathrm{C}$ plane, and the hexagons being formed from the rhombic plates by truncating the acute angles by faces parallel to the intersection of the $\mathrm{C}$ plane by the plane of symmetry.

The planc angles of the rhombic plates, calculated from the numbers given by Rammelsberg, are $100^{\circ} 56^{\prime}$ and $79^{\circ} 4^{\prime}$, while the hexagonal plates present end-angles of $100^{\circ} 5^{\prime}$ and four side-angles of $129^{\circ} 32^{\prime}$. These angles are sufficiently different to allow in most cases the principal plane of a plate, or even of a fragment of a plate, to be determined at once by inspection. But in any case of doubt it may readily be found without breaking the crystal by examining it in polarised light. There are

${ }^{x}$ Paper read at the Royal Society on March 19 by Prof. G. G. Stokes, Cambridge. 
good cleavages parallel to the two $\mathrm{P}$ planes and to the $\mathrm{C}$ plane. The crystals are very commonly twinned, the twin plane being $\mathrm{C}$.

2. If one of the brilliantly coloured crystals be examined by reflection, and turned around in its own plane, without altering the angle of incidence, the colour disappears twice in a complete revolution. The vanishing positions are those in which the plane of incidence is the plane of symmetry. The colour is perhaps most vivid in a perpendicular plane; but for a very considerable change of azimuth from the perpendicular plane there is little variation in the intensity of the colour. 'Ihere is no perceptible change of tint, but on approaching the plane of symmetry the colour gets morc and inore drowned in the white light reflected from the surface.

3. If instead of altering the azimuth of the plane of incidence a plane be chosen which gives vivid coluar, and the angle of incidence be altered, the colour changes very materially. If we begin with a small angle the colour begins to appear while the angle of incidence is still quite molerate. What the initial colour is, varies from one crystal to another. As we increase the angle of incidence the colour becomes vivid, at the same time changing, and as we continue to increass the angle the change of colonr goes on. The change is always in the order of increasing refrangibility; for example, from red through green to blite. Not unfrequently, however, the initial tint may be green or biue, and on approaching a grazing incidence we may get red or even yellow mixed with the blue, as if a second order of colours were commencing.

4. The colours are not in any way due to absorption; the transmitted light is strictly complemcntary to the reflected, and whatever is missing in the reflected is found in the transmitted. As in the case of Newton's rings, the reflected tints are much more vivid than the transmitted, though, as will presently appear, for a very different reason.

5. As Dr. Herepath remarked to me long ago, the colourd light is not polarised. It is produced indifferently whether the incident light be common light or light polarised in any plane, and is seen whether the reflected light le viewcd dircctly or through a Nicol's prism tumed in any way. The only difference appears to be that if the incident light be polarised, or the reflected light analysed, so as to furnish or retain light polarised perpendicularly to the plans of incidence, the white light reflected from the surface, which to a certain extent masks the coloured light, is more or less got rid of

6. The character of the spectrum of the reflected light is most remarlkable, and was wholly unexpected. A direct-vision hand spectroscope was used in the observations, and the crystal was generally examined in a direction roughly perpendicular to the plane of symmetry; hut it is shown well through a. wide range of azimuth of the plane of incidence. No two crystals, we may say, are alike as to the spectrum which they show, but there are certain features common to all. The remarkahle feature is that there is a pretty narrow band, or it may be a limited portion of the spectrum, but still in gencral of no great extent, where the light suffers total or all but total reflection. As the ang'e of incidence is increascd, thesc bands move rapidly in the direction of increasing refrangibility, at the same time increasing in width. The character of the spectrum gradually changes as the angle of incidence is increased; for example, a a single band may divide into two or three bands.

The bands are most sharply defined at a moderate angle of incidcnce. When the angle of incidence is considerably in creased, the bands usually get somewhat vague, at least towards the edges.

7. The commonest kind of spectrum, especially in crystals prepared on a small scale, which will he montioned presently, is onc showing only a single tright band; and I will describe at greater length the phenomena presented in this case.

When the angle of incidence is very small, the light reflected from the reflecting surfaces of the crystal shows only a continuous spectrum, As the angle of incidence is increased, while it is still quite moderate a very narrow bright band shows itself in some part of the spectrum. The particular part varies from one crystal to another ; it may be anywhere from the extreme red to the extreme violet. It stands out by its greatly superior brightness on the general ground of the continuous spectrum, and when it is fully formed the reflection over the greater part of it appears to be total. The appearance recalls that of a bright band such as the green band seen when a calcium salt, or the orange band seen when a strontimm salt, is put into a Bunsen flame. The bright band is frequently accompanied right and left by maxima and minima of illumination, forming bands of altogelher subordinate importance as regards their illumination. Sometimcs these seem to be absent, and I cannot say whether they are an essential feature of the phenomenon, which somelimes fail to be seen because the structure on which the bands depend is not quite regularly formed, or whether, on the other hand, they are something depending on a different cause.

Disregarding these altogether subordinate bands, and taking account of the mean illumination, it seems as if the brightness of the spectrum for a little way right and left of the bright band were somcwhat less than that at a greater distance.

When the main band occurs at either of the faint onds of the spectrum, it is visible, by its superior brightness, in a region which, as regards the continuous spectrum, is too faint to be seen, and thus it appears separated from the continuous spectrum by a dark interval.

When the angle of incidence is increascd, the band moves in the direction of increasing refrangilitity, and at the same time increases rapidly in breadth. 'The increase of breadth is far too rapid to be accounted for merely as the result of a different law of separation of the colours, which in a diffraction spectrum would be separated approximalcly according to the squared reciprocal of the wave-length, while in bands depending on direct interference the phase of illumination would change according to the wave-length.

8. The transmitted light heing complementary to the incident, we have a dark band in the transmitted answering to the bright band in the reflected. In those crystals in which the band is best forncel, it appears as a narrow black band even in bright light. When the band first appears as we recede from a normal incidence it is extremely narrow, but it rapidly increases in breadth as the angle of incidence is increased.

9. Some of the general features of the phenomenon were prettily shown in the followings experiment :-

Choosing a crystal in which the bright band in the reflected light began to appear, as the incidence was increased, on the red side of the line D, so that un continuing to increase the incidence it passed through the place of the line $D$ before it had become of any grat width, I viewed through the crystal a sheet of white paper illuminated by a soda flame. $\Lambda$ dark ring was seen on the paper, which was circular, or nearly so, and was interrupted in two places at opposite extremitics of a diameter, namely, the places where the ring was cut by the planc of symmetry. The light of the refrangibiity of $D$ was so nearly cxcluded from the greater part of the ring that it appeared nearly black, though slightly bluish, as it was illuminated by the feeble radiation from the flame belonging to refrangibilities other than those of the immediate neighbourhood of $D$. The ends of the two halves of the sing became feeble as they approached the plane of symmetry. $\Lambda$ subordinate comparatively faint ring lay in this crystal immediately outside the main one.

Io. Suspecting that the production of colour was in some way connected with twinning, I examined the cleft edge of some of the crystals which happened to have been brolsen across, and found that the bright reflection given by the exposed surface was interrupted by a line, much finer than a hair, running paralle to the $C$ faces, which could be easily scen with a watchmaker's Icns, if not with the naked eye. This line was dark on the illuminated bright surface exposed by clcavage, a surface which I supposc illuminated by a source of light not too large, such as a lamp, or a window at somc distance. The plane of incidence being supposed no:mal to the intersection of the rlearage plane by the $C$ faces, on tuming the crystal in a proper direction around a normal to the plane of incidence, the light ceased to be re flected from the cleavage surface, and after turning through a certain angle, the narrow line which previously had been dark was scen to glisteri, indicating the existence of a reflecting surface, though it was much too narrow to get a reflected image from off it. The dircction of rotation required to make the finc line glisten was what it ought to be on the supposition that the fine line was the cleavage face of an extremcly narrow twin stratum.

II. On examining the fine line under the microscope, it was found to be of different thichnesses in different crystals, though in those crystals which showed colour it did not vary very greatly. On putting a little lycopodium on the cleavage face interrupted by the fine line, it was seen that in those crystals which showed colour the breadth of the twin stratum varied from a little greater to a little less than the breadth of a spore. 'The thickness 
accordingly ranged somewhere about the thousandth of an inch, such being the diameter of the spores. The stratum was visibly thicker in those crystals which showed their bright band in the red than in those which showed it in the blue.

12. That the thin twin stratum was in fact the seat of the colour, admitted of being proved by a very simple experiment. It was sufficient to hold a needle, or the blade of a penknife (I will suppose the latter), close to or touching the surface of the crystal while it was illuminated by light coming approximately in one direction, suppose from a lamp, or from a window a little way off, and to examine the shadows with a watchmaker's lens. The light reflected from the crystal comes partly from the upper surface, partly from the twin stratum, partly from the under surface, which, however, may be too irregular to give a good reflection. The twin stratum is much too thin to allow of separating the light reflected from its two surfaces in an observation like the present, and it must therefore be spoken of as simply a reflecting surface. Corresponding to the three reflecting surfaces are three shadows, where the incident light is cut off: (I) from the upper surface, (2) from the twin stratum, (3) from the under surface. By examining these shadows in different crystals and under varied conditions, it is shown beyond doubt that the coloured reflection comcs from the twin stratum.

The conclusion was confirmed by observations made with sunlight; but the simple method of shadows is quite as good, and even by itself perfectly satisfactory.

I3. Another useful method of observation, not so very simple as the last, is the following. A slit, suppose horizontal, not very narrow, is placed in front of the flame of a lamp at some distance, and an image of the slit is formed by a suitable lens, such as the compound achromatic objective of an opera-glass. The crystal is placed so as to receive in focus the image of the slit, being inclined at a suitable angle, usually in a plane perpendicular to the plane of symmetry. The eye is held in a position to catch the reflected light, and the images formed by the different reflections are viewed through a watchmaker's lens. If the slit be not too broad, the images formed by reflection from the upper surface, from the twin stratum, and from the under surface are seen distinet from each other, so that the light reflected from the twin stratum may be studied apart from that reflected from the upper and under surfaces.

In this mode of observation it can readily be seen, by turning the crystal in its own plane, and noticing the middle image, which is that reflected from the twin stratum, how very small a rotation out of the position in which the plane of incidence had been the plane of symmetry suffices to re-introduce the coloured light, which had vanished in that critical position, which appears to be a position not merely of absence of colour, but of absence of light altogether; at least if there be any it is too fceble to be seen in this mode of observation, though from theoretical considerations we should conclude that there mast be a very little reflected light, polarised perpendicula:ly to the plane of incidence.

14. On allowing a strong solution of chlorate of potash in hot water to crystallise rapidly, in which case excessively thin plates are formed in the bosom of the liquid, I noticed the play of colours by reflection mentioned by Professor Mills as belonging to the crystals in general at an early stage of their growth. This, however, proved to be quite a different and no doubt a much simpler phenomenon. The difference was shown by the polarisation of the light, and above all by the character of the spectrum of the light so reflected, which resembled ordinary spectra of interference, and did not present the rcmarkable character of the spectra of the peculiar crystals.

15. When, however, the whole was left to itself for a day or so, among the mass of usually colourless crystals a few were found here and there which showed brilliant colours. These colours were cornmonly far more brilliant than those of the crystals mentioned in the preceding paragraph, and they showed to perfection the distinctive character of the spectrum of the peculiar crystals. It would have becn very troublesome, if possible at all, to examine the twinning of such thin and tender plates as those thus obtained by working on a small scalc; but the character of the spectrum, which is perhaps the most remarkable feature of the phenomenon, as well as the dependence of the colour on the orientation, may be examined very well ; and thus any one can study these features of the phenomenon, though he may not have access to such fine coloured crystals as those sent me by Professor Mills.

16. A certain amount of disturbance during the early stages of crystallisation, whether from natural currents of convection or from purposely stirring the solution, somewhat gently so as not to break the crystals, seems favourable to the production of the peculiar crystals. When the salt crystallised slowly from a quiet solution I did not obtain them.

I7. As it is easy in this way, by picking out the peculiar crystals from several crystallisations, to obtain a good number of them, the observer may satisfy himself as to the most usual character of the spectrum. It is best studied at a moderate incidence, as it? is sharper than when the incidence is considerable.

I8. The number of coloured crystals obtained by crystallisations on a small scale, though very small, it is true, compared with the number of colourless ones, was still so much larger than Prof. Mills's description of the rarity of the crystals had led me to expect, that $I$ at one time doubted whether the simply twinned crystals which are so very common, if taken at a period of their growth when one component is still very thin, and of suitable thickness, might not possibly show the phenomenon, though the thin twin was in contact on one face only with the brother twin, the other face being in the mother-liquor or in air. The circumstances of reflection and transmission at the first surface of the twin plate must be very different according as it is in contact with the brother crystal, or else with the motherliquor, or air, or some other fluid ; and yet the peculiar spectrum was shown all the same whether the crystal was in air, or immersed in the mother-liquor, or in rock oil. However, to make sure of the matter I took a simply twinned crystal, and ground it at a slight inclination to the $\mathrm{C}$ face till the twin plane was partly ground away, thus leaving a very slender twin wedge forming part of the compound crystal, and polished the ground surface. On examining the reflected light with a lens, no colour was seen about the edge of the wedge, where the thickness of the wedge tapered away to nothing; and that, although the bands seen near the edge in polarised light, which was subsequently analysed, showed that had colours been producible in this way, as they are by a thin twin stratum, they would not have been too narrow to escape observation.

In another experiment a simply twinned crystal was hollowed out till the twin plane was nearly reached. The hollowing was then continued with the wetted finger, so as to leave a concave smooth surface, the crystal being examined at short intervals in polarised light as the work went on, so as to know when the twin plane was picrced. But though in this case the twin plane formed a secant plane, nearly a tangent plane, to the worked surface, and near the section the twin portion of the crystal must have been very thin for a breadth by no means infinitesimal, as was shown by examination in polarised light, yet no colours were scen by reflection. I conclude therefore that the production of these coluurs require: the twin stratum to be in contact on both its faces with the brother crystal.

19. The fact that a single bright band is what most usually presents itself in the spectrum of the reflected light, though sometimes two or three such bands at regular intervals may be seen, seems to warrant us to regard that as the kind of spectrum belonging to the simplest form of twin stratum, namely, one in which there are just the two twin surfaces near together. The more complicated spectra seem to point to a compound interference, and tu be referable to the existence of more than two twin planes very near together; and in fact in some of the crystals which showed the more complicated spectra, and which wcre broken across, I was able to make out under the microscope the existence of a system of more than two twin planes close together. Restricting ourselves to what may be regarded as the normal casc, we have then to inquire in what way the existence of two twin planes near together can account for the peculiar character of the spectrum of the reflected or transmitted light.

Section II. - Of the Proximate Cause of the Phenomenon.-20. Though I am not at present prepared to give a complete explanation of the very curious phenomenon $I$ have described, I have thought it advisable to bring the subject before the Society, that the attention of others may be directed to it.

That the seat of the coloration is in a thin twin stratum, admits I think of no doubt whatsoever. A single twin plane does not show anything of the kind.

For the production of the colour the stratum must be neither too thick nor too thin. Twin strata a good deal thicker than those that show colour are common enough; and among the crystals sent to me I have found some twin strata which were a good deal thinner, in which case the crystal showed no colour. 
'The more complicated spectra which are frequently observed seem referable to the existence of more than two twin planes in close proximity. There is no reason to think that the explanation of these spectra would involve any new principle not already contained in the explanation of the appearance presented when there are only two twin planes, though the necessary formula would doubtless be more complicated.

Corresponding to a wave incident in any direction, in one component of a twin, on the twin plane, there are in general two refracted waves in the second component in planes slightly inclined to each other, and two reffected waves which also have their planes slightly inclined to each other, the angle of inclination, however, being by no means very small, as chlorate of potash is strongly double refracting. The planes of polarisation of the two refracted waves are approximately perpendicular to each other, as are also those of the two reflected waves; but on account of the different orientation of the two components of the twin, the planes of polarisation of the two refracted waves are in general altogether different from those of the incident wave and of its fellow, the tracc of which on the twin plane would travel with the same velocity. In the plane of symmetry at any incidence, and for a small angle of incidence at any azimuth of the plane of incidence, the directions of the planes of polarisation of the two refracted waves agree accurately or nearly with those of the incident wave and its fellow. In these cases, therefore, an incident wave would produce hardly more than one refracted wave, namely, that one which nearly agrees with the incident wave in direction of polarisation. In these cases the colours are not produced. It appears, therefore, that their production demands that the incident wave shall be very determinately divided into two refracted wave, accompanied of course by reflected waves.

It seems evident that the thickness of the stratum affects the result through the difference of phase which it entails in the two refracted waves on arriving at the second twin plane. But whereas in the ordinary case of the production of colour by the interposition of a crystalline plate between a polariser and an analyser, we are concerned only with the difference of retardation of the differently polarised pencils which are transmitted across the plate, and not with the absolute retardation, it is possible that in this case we must take into account not only the difference of retardation for the differently polarised pencils which traverse the stratum, but also the absolute retardation that is, the retardation of the light reflected from the second relatively to that reflected from the first twin plane.

2I. I have not up to the present seen my way to going further It is certainly very extraordinary and paradoxical that light sh:suld suffer total or all but total reflection at a transparent stratum of the very same substance, merely differing in orientation, in which the light had been travelling, and that, independently of its polarisation. It can have nothing to do with ordinary total internal reflcction, since it is observed at quite moderate incidences, and only zeithin very narrow limits of the angle of incidence.

\section{RECENT PROGRESS IN CHEMISTRY}

TIIE progrcss of chemistry during the last year has been considerable, and a great deal of interesting and important work has been done. Nevertheless it cannot be said to have been a year productive of any very special discoveries. In physical chemistry the subjects connected with heat have occupied a good deal of attention, such as the heat of formation of chemical compounds, \&c. Experiments on the liquefaction and solidification of gases by pressure and low temperature have also been continued, and, in addition to the results which were obtained some time since, we now know chlorine, not only as a liquid, but also as a crystalline solid. The same is true of hydrochloric acid, carbonic oxide, silicon fuoride, and assinuretted hydrogen.

Last year I referred to the work which was being done with hydroxylamine, and also mentioned that another analytical reagent of equal importance was claiming attention, viz. Emi Fischer's phenylhydrazine. The promise of new work which this substance gave has been fully realised, and it has proved useful, not only as an analytical reagent, but has been the means of producing a number of new and important products.

Work is still actively pursued on the pyrroline, pyridine, and ${ }^{x}$ From the Annual Address of the President of the Chemical Society, Mr. W. II. Perkin, F.R.S., March 30, 2885 . quinoline series, and it is remarkable to see how new methods for the production of bodies of this description are being constantly discovered. Those of A. Behrmann and Hofmann, who obtain pyridine derivatives from citramide, and of $\mathrm{H}$. v. Pechmann, who obtains them from malic acid, may be taken as illustrations.

It is interesting to notice, in reference to the pyridine serics, Iadenburg's experiments (Ber., xvii. $772-74$ ), who finds that the compounds formed by the union of these bases with the iodirles of the alcohol radicals, when strongly heated, yield substituted pyridines in the same way as Hofmann showed some time since that aniline, under like circumstances, yielded substituted anilines, such as toluidine, \&c. Hofmann (Ber., xvii. 1200 ) has also found that conine hydrochloride, when distilled with zinc dust, yields a base he has named conyrine, which he belicves to be a propyl or isopropyl pyridine; and this, by treatment with hydriodic acid at $280^{\circ}-300^{\circ}$, regencrates conine which has exactly the same physiological action as the natural (though it is probably optically inactive). I adenburg (Ber., xvii. I I 96 ) has obtained a propylpyridine which, when treated with sodium and alcohol, yields a base smelling very much like conine; it has many properties in common with conine, and, like it, is poisonous, acting in the same manner and to the same degree. It is, however, optically inactive, as might be expected. It will be remembered that Schiff (Ann. Ch. Pharm., clvii, 352) obtained a base very similar to conine from isobutyric aldehyde and ammonia some years ago, but it did not appear to agree in all its properties with that body. From the new work which has been done in this subject we may now soon expect to have the constitution of this base definitcly established. Ladenberg has also succeeded in producing piperidine from pyridine. The identity of this product with that obtained from piperine from pepper has been establisher (Ber., xvii. 513-5I5).

Ilofmann, while continuing his work on the action of bromine in alkaline solutions in amides, has found the curious fact that nitrilcs are produced in considerable quantities containing one atom of carbon less than the amide-in fact, corresponding with the amines formed in the reaction, and are, in all probability, produced from them by the removal of the hydrogen atoms. As these nitriles can be converted into amides by sulphuric acid, and again treated with bromine and alkali, it is evident that by this means we can gradually work down step by step from one member of the homologous series to another.

It will be remembered that Pechmann and Duisberg (Ber., xvi. $2119-2128$ ) succeeded in obtaining substituted coumarins and their hydroxy derivatives by acting on accto and benzoylacetic acids with phenols. Pechmann (Ber., xvii. 929.936) has now succeeded in obtaining coumarins by treating malic acid and phenols with sulphuric acid or chloride of zinc; with ordinary phenol he has obtained coumarin; with resorcinol, umbelliferone and with pyragallol, daphnetin, which gives all the reactions of the natural body.

Some very curious results have lately been obtained in reference to the destructive action of aluminium chloride on hydrocarbons. Friedel and Crafts communicated a paper on this subject to this Society in 1882 ; it has now been further studied by Auschiitz, Immerdorff, and by Jacobson (Ber., xviii. 657). They have found that this action consists in "a transference of the alcohol radical from one molecule of a hydrocarbon to another molecule of the same hydrocarbon." Thus toluene yields, on the one hand, benzene, and on the other, xylene and more highly methylated benzenes, orthoderivatives being very rarely foind among the products.

Iast ycar I rcferred to the discovery of thiophene, or, more properly, thiophen, and its homologues by Victor Meyer. During the year our knowledge of this interesting body has been considerably extended, and its preparation rendered comparatively easy. H. E. Schulze (Ber., xviii. 497) has recently thown that it is contained-as might be expected-in the sulphuric acid used to purify crude benzene, and that if its decomposition be prevented by diluting the acid with an equal bulls of water as soon as it is separated from the benzene, the thiophen which is doubtless present in the form of a sulpho acid may easily be recovered by hydrolysing, by merely passing steam into the acid liquid.

The synthesis of thiophen, recently effected by J. Volhard and $\mathrm{H}$. Erdmann (Bcr., xviii. 454) by merely distilling sodium succinate with phosphorus trisulphide (by which about 50 per cent. of the theoretical yield is obtained), is also of interest, as well as the production of methylthiophen from sodium pyro- 